\title{
Effect of the composite curing light mode on polymerization shrinkage of resin composites
}

\author{
Özden Özel Bektas, DDS, PhD, Feridun Hürmüzlü, DDS, PhD, Diğdem Eren, DDS, PhD
}

Cumhuriyet University, Faculty of Dentistry, Department of Restorative Dentistry, Sivas.

Received: 24 March $2011 \quad$ Accepted: 12 July 2011

\begin{abstract}
Objectives: The aim of this study was to investigate the effects of light curing method on the polymerization shrinkage of composite resins.

Materials and Methods: Eight methods of four different light curing units were tested by forming 16 groups using two different composite types. Resin composite specimens weights were determined with an analytical electronic hydrostatic balance in the air and in water before and after curing. Then specific gravity values were determined. Volumetric polymerization shrinkage was calculated using mathematical formulas.

Results: According to the results of this in-vitro study, polymerization shrinkage differed significantly among the light curing units.

Conclusions: When the amount of polymerization shrinkage was compared, it was determined that the curing method, which has the greatest total energy density, caused the greatest amount of shrinkage. It was also found out that some of the curing units affected the shrinkage positively in soft-start mode.

Key words: Composite resin, curing light, polymerization shrinkage, light intensity, total energy.
\end{abstract}

\section{INTRODUCTION}

Light-activated composites revolutionized modern restorative dentistry in the mid-1960s and have undergone improvements in performance characteristics such as esthetics, wear rate, and handling since then ${ }^{1}$.

In recent years, with the development of nanotechnology, a new breed of composite resins, termed "nanofill composites", has been introduced into the dental market. Nanofill composites were first mentioned in the early $1990 \mathrm{~s}^{2}$ but the first commercial product (Filtek Supreme, 3MESPE) was launched in late 2002. ${ }^{3}$ Nanosized inorganic fillers enable the filler content of composite pastes to be maximized while retaining excellent

Ozden OZEL BEKTAS

Cumhuriyet University

Faculty of Dentistry

Department of Restorative Dentistry

Sivas, TURKEY

Tel: +90346 2191010-2791

Fax: +903462191237

e-mail:ozdenozel@hotmail.com clinical handling properties and at the same time minimizing the percentage of organic resin matrix. This results in dental filling composites with greatly improved mechanical properties. ${ }^{4}$

Although the properties of modern resin composites have improved, polymerization shrinkage is still a clinically significant problem. It creates contraction stress in the resin composite restoration and internal stress and deformation in the surrounding tooth structure. ${ }^{5}$

The polymerization shrinkage of dental composite resins is influenced by numerous parameters such as inorganic filler content, the molecular weight of the monomer system, and the degree of conversion of the monomer system. ${ }^{6}$ Several approaches are being pursued to reduce the polymerization shrinkage in dental resins. The aspect of polymerization under the greatest control of the clinician is the application of the curing light. ${ }^{7}$

A recent method to minimize polymerization shrinkage without affecting the degree of conversion of light-activated composites is controlled polymerization. 
The light intensity $\left(\mathrm{W} / \mathrm{cm}^{2}\right)$, also referred as power density or irradiance, is the number of photons per second (W) received by a square centimeter of the target, e.g., the surface of the resin. The total energy (energy density) $\left(\mathrm{J} / \mathrm{cm}^{2}\right)$ is calculated by multiplying the intensity by the total exposure time in seconds. ${ }^{8}$ If the equivalent total energy was irradiated to the resin, the degree of conversion might be the same regardless of the differences in the light intensity or irradiation time. ${ }^{9}$

Controlled polymerization can be achieved by the application of short pulses of energy (pulse) or pre-polymerization in low-intensity light followed by a final cure in high-intensity light with a soft-start technique (two-step and ramped/exponential) or a combination of the two (pulse delay). ${ }^{10}$

While some studies have shown that these polymerization modes may result in smaller marginal gaps and increased marginal integrity, ${ }^{11,12}$ others have found no significant improvement in marginal adaptation. $^{13}$

Beside the curing techniques, clinicians face many choices when selecting a curing unit. The choices of contemporary light sources include quartz tungsten-halogen (QTH) units, light-emitting diodes (LEDs), plasma-arc curing (PAC) lights, and argonion lasers.

Halogen light-curing units are currently the most commonly used means of curing dental composites, ${ }^{14}$ and LEDs are considered to be a promising technology for polymerization of resin dental materials. $^{15}$

Under the light of all expressions above, the aim of this study was to evaluate the polymerization shrinkage of a nanofill and a microhybrid composite resins cured with different lights curing units (halogen and LED) and different modes (standard, softstart, and pulse).

\section{MATERIALS AND METHODS}

To conduct this study, a microhybrid resin composite (Venus) and a nanofill resin composite (Filtek Supreme) were used. The materials' manufacturers, composition, shade, and batch numbers are listed in Table 1. In addition, four curing units (Hilux, Translux, Elipar Freelight, and Mini L.E.D) were used to compare their curing methods. Table 2 describes the curing lights (modes and manufacturers) tested. To assess the effects of different light curing methods on polymerization shrinkage of resin composites, factors that influence the polymerization shrinkage of composite resin, namely the thickness, the color of the restorative material, and the distance of the light tip to the restoration surface, were all standardized in the present study.

Volumetric polymerization shrinkage was determined using the density measurement technique. To shape the composite specimens, a stainless steel ring $4 \mathrm{~mm}$ in diameter and 2-mm thick was used together with a glass section and mylar strip. Shade A2 of both materials were placed into the ring. Five specimens were prepared from each of the eight curing modes.

Each specimen was expressed carefully from one side of the mold and weighed twice in an analytical electronic balance with an accuracy of $0.0001 \mathrm{~g}$ and a specific gravity measuring kit (Precisa Model XB220A, Switzerland). The specimens were first weighed in the air and then in distilled water following a method similar to that used by Puckett \& Smith.[16] Specimens were dried carefully with absorbent paper and then subjected to one of the eight light curing methods listed below. Curing profiles are based on manufacturers' information. Intensity of all light curing unit checked with the in-built radiometer prior to use. The distance between source and specimen was standardized by using a 1-mm glass slide. The end of the light guide was in contact with the cover glass during the lightpolymerization process.

Method 1: Hilux curing light, continuous output at $500 \mathrm{~mW} / \mathrm{cm}^{2}$ for $40 \mathrm{~s}$; 
Method 2: Translux curing light, continuous output at $900 \mathrm{~mW} / \mathrm{cm}^{2}$ for $40 \mathrm{~s}$; Method 3: Translux curing light, ramp output from 200 to $900 \mathrm{~mW} / \mathrm{cm}^{2}$ in $15 \mathrm{~s}$, then $25 \mathrm{~s}$ at $900 \mathrm{~mW} / \mathrm{cm}^{2}$;

Method 4: Elipar Free Light curing light, continuous output at $400 \mathrm{~mW} / \mathrm{cm}^{2}$ for $40 \mathrm{~s}$; Method 5: Elipar Free Light curing light, ramp output from 0 to $400 \mathrm{~mW} / \mathrm{cm}^{2}$ for 12 $\mathrm{s}$, then $28 \mathrm{~s}$ at $400 \mathrm{~mW} / \mathrm{cm}^{2}$;

Method 6: Mini LED curing light, continuous output at $1100 \mathrm{~mW} / \mathrm{cm}^{2}$ for 20 $\mathrm{s}$;

Method 7: Mini LED curing light, softstart output from 0 to $1100 \mathrm{~mW} / \mathrm{cm}^{2}$ in 10 $\mathrm{s}$, then $10 \mathrm{~s}$ at $1100 \mathrm{~mW} / \mathrm{cm}^{2}$;

Method 8: Mini LED Pulse output at 1100 $\mathrm{mW} / \mathrm{cm}^{2}$ for $40 \mathrm{~s}(1 \mathrm{~s}$ light on and $1 \mathrm{~s}$ light off).

Specimens were weighed immediately after light curing. The weights of each specimen in the air and water were used to calculate specific gravity values before and after curing. These values were used to determine volumetric shrinkage according to the following formulas:

SG 1 = M1/(M1-M2) (1);

SG2 $=$ M3/(M3-M4) (2)

$\mathrm{SG} 1=$ specific gravity before polymerization

SG $2=$ specific gravity after polymerization

M1 = mass of specimen weighed in air before polymerization

M2 = mass of specimen weighed in the water before polymerization

M3 = mass of specimen weighed in air after polymerization

M4 = mass of specimen weighed in the water after polymerization

Density of specimen $\left(\mathrm{kg} / \mathrm{cm}^{3}\right)=\mathrm{SG} \mathrm{x}$ density of the water at $23^{\circ} \mathrm{C}$

V1 $=$ M1/D1 (3)

$\mathrm{V} 2=\mathrm{M} 3 / \mathrm{D} 2$ (4)

$\mathrm{V} 1=$ Volume of specimen before polymerization

$\mathrm{V} 2=$ Volume of specimen after polymerization

D1 = Density of specimen before polymerization
D2 = Density of specimen after polymerization

Percentage contraction $=(\mathrm{V} 2-\mathrm{V} 1) / \mathrm{V} 2 \mathrm{x}$ $100(5)$

To calculate the total energy, the intensity of the curing light (in $\mathrm{mW} / \mathrm{cm}^{2}$ ) and the duration of exposure (in seconds) were used. The total energy is expressed in Joules per spot size area $\left(\mathrm{cm}^{2}\right)$ and is described by the following equation.

Total energy $=($ Watts $X$ seconds $) \backslash \mathrm{cm}^{2}$ $=$ Joules $\backslash \mathrm{cm}^{2}$

Data were subjected to statistical analysis using ANOVA and Tukey's test to determine possible statistical differences among the groups tested in this study at the 0.05 level of significance.

\section{RESULTS}

The mean values and standard deviation of the volumetric polymerization shrinkage are shown in Table 3. According to the tests, there was a statistically significant difference among the light curing lights $(p<0.05)$ tested. For Filtek Supreme composite resin groups; Method 2 showed the highest polymerization shrinkage, with a significant statistical difference from Method 1, Method 5, Method 7, and Method 8. Also, Method 6 caused higher mean polymerization shrinkage, with a significant difference from Method 8. For Venus composite resin groups; the mean polymerization shrinkage of Method 2 was significantly different from that of Method 4 and Method 5. Comparing shrinkage values of the two composites cured with the same mode revealed that there was no significant difference $(p>0.05)$.

\section{DISCUSSION}

The polymerization of a composite material is accompanied by volume reduction, which is seen as contraction stress at the contact area to the tooth. The forces developed thereby can affect the filling material-tooth junction. ${ }^{17}$ In this study it was shown that total energy of curing methods might have an adverse 
effect on polymerization shrinkage of composite resins.

Various techniques have been developed to measure the polymerization shrinkage of composites. Most are based on measuring the volumetric changes by using dilatometry (with mercury or water). The major problem with this method is the difficulty in getting light source to reach the immersed composite specimen and, in the case of mercury dilatometer, the manipulation of hazardous material. ${ }^{18,19}$ The density measurement was used for determining volumetric shrinkage. This method is simple, accurate, and reproducible since it does not require the use of elaborate equipment. ${ }^{16,19}$

Miyazaki and others, ${ }^{20}$ who used a dilatometer method, reported a positive correlation between the volumetric polymerization shrinkage of three compomers and light intensity. Also, Santos and others, ${ }^{19}$ evaluated the effect of light curing method on volumetric shrinkage of three resin composites. They claimed that in spite of variability in total energy of four curing methods, this difference had little or no effect on volumetric polymerization shrinkage for most composite/curing methods.

On the other hand, Baek and others ${ }^{21}$ have reported that total energy played a more influential role in polymerization shrinkage than light intensity. Maximum polymerization shrinkage also reached a higher value at a higher total energy as compared to the case of lower total energy. This finding compares well with those of the current study.

In this study, standard mode of Translux curing light resulted in higher polymerization shrinkage in both composite resins. The total energy emitted by this curing regime was $36 \mathrm{~J} / \mathrm{cm}^{2}(900$ $\mathrm{mW} / \mathrm{cm}^{2} \times 40 \mathrm{~s}$ ). Groups cured with this curing regime show significantly higher shrinkage than the groups cured with the total energy less than approximately 20 $\mathrm{J} / \mathrm{cm}^{2}$.
Furthermore, total energies delivered by pulse mode and standard mode of the Mini LED curing light were approximate equal. However, the pulse mode produced lower polymerization shrinkage than the standard mode. This difference was significant, especially in the Filtek Supreme group. While using the pulse mode, the photoactivation occurs in cycles, inserting intervals of light-on and light-off. ${ }^{22,23}$ It is important to point out that energy loss occurred during each cycle is to be considered when calculating the total energy. Energy loss occurs because of the fact that in each cycle, when the light turns on, the total energy is reduced. ${ }^{23}$ The higher total energy in standard mode is thought to be the cause of the higher polymerization shrinkage than those obtained in pulse mode.

While some studies have shown that modulated polymerization modes result in lower shrinkage, ${ }^{24,25} \mathrm{Yap}^{26}$ observed no significant reduction in polymerization shrinkage with soft-start curing modes. Furthermore, Koran and Kurschner ${ }^{27}$ evaluated the effect of standard and softstart curing modes on the polymerization shrinkage of resin composites. They reported that although the dynamics of polymerization shrinkage were better with the soft-start curing mode, the overall final polymerization shrinkage was equal for the two curing methods.

In our study, the soft-start and standard curing techniques resulted in similar polymerization shrinkage. However, when compared to the standard modes of all curing lights used in this study, although differences were not significant, less contraction was produced in soft-start mode.

Previous studies showed that increasing light intensity resulted in more polymerization shrinkage for some composites, but not all materials. ${ }^{22,26}$ In our study, the effects of each curing mode on two composite resins were compared and no significant difference was observed. Each composite showed similar behavior 
in the face of modulation of the light intensity during photoactivation. Therefore, it must be put into perspective that this result is valid only for two resin composites in this study.

Consequently, within the limitations of this study, it can be concluded that the increase in the shrinkage of composites is related to the total energy of curing lights. Further research in this area is necessary in order to reveal the polymerization shrinkage of other composite resins.

\section{REFERENCES}

1. Tolidis K, Nobecourt A, Randall R. Effect of a resin-modified glass ionomer liner on volumetric polymerization shrinkage of various composites. Dent Mater 1998;14(6):417-423. [CrossRef]

2. Bayne SC, Heymann HO, Swift EJ Jr. Update on dental composite restorations. J Am Dent Assoc 1994;125(6):687-701.

3. Yap AU, Tan CH, Chung SM. Wear behavior of new composite restoratives. Oper Dent 2004;29(3):269-274.

4. Yap AU, Lim LY, Yang TY, Ali A, Chung SM. Influence of dietary solvents on strength of nanofill and Ormocer composites. Oper Dent 2005;30(1):129-133.

5. Braga RR, Ferracane JL. Alternatives in polymerization contraction stress management. Crit Rev Oral Biol Med 2004;15(3):176184. [CrossRef]

6. Peutzfeldt A. Resin composites in dentistry: The monomer systems. Eur J Oral Sci 1997;105(2):97-116. [CrossRef]

7. Sakaguchi RL, Berge HX. Reduced light energy density decreases postgel contraction while maintaining the degree of conversion in composites. J Dent 1998;26(8):695-700. [CrossRef]
8. Craig RG, Powers JM. Restorative dental materials. 2002; Mosby, St. Louis.

9. Nomoto R, Uchida K, Hirasawa T. Effect of light intensity on polymerization of light cured composite resins. Dent Mater J 1994;13(2):198-205.

10. Soh MS, Yap AUJ. Influence of curing modes on crosslink density in polymer structures. J Dent 2004;32(4):321-326. [CrossRef]

11. Mehl A, Hickel R, Kunzelmann KH. Physical properties and gap formation of light-cured composites with and without "soft-start polymerization" J Dent 1997;25(34):321- 330.

12. Kanca J, Suh BI. Pulse activation: Reducing resin-based composite contraction at the enamel cavosurface margins. Am J Dent 1999;12(3):107-112.

13. Friedl KH, Schmaltz G, Hiller KA , Markl A. Marginal adaptation of Class V restorations with and without "softstart" polymerization. Oper Dent 2000;25(1):26-32.

14. Oberholzer TG, Pameijer $\mathrm{CH}$, Grobler SR, Rossouw RJ. The effect of different power densities and method of exposure on the marginal adaptation of four light-cured dental restorative materials. Biomater 2003;24(20):3593-3598. [CrossRef]

15. Yap AUJ, Soh MS, Han VTS, Siow KS. Influence of curing lights and modes on cross-link density of dental composites. Oper Dent 2004;29(4):410-415.

16. Puckett AD, Smith R. Method to measure the polymerization shrinkage of light-cured composites. J Prosthet Dent 1992;68(1):56-58. [CrossRef]

17. Ilie N, Kunzelmann KH, Hickel R. Evaluation of micro-tensile bond strengths of composite materials in comparison to their polymerization 

shrinkage.
Dent
Mater
2006;22(7):593-601. [CrossRef]

18. Watts DC, Cash AJ. Determination of polymerization shrinkage kinetics in visible-light-cured materials: methods development. Dent Mater 1991;7(4):281-287. [CrossRef]

19. Coelho Santos MJ, Santos GC JR, Nagem Filho H, Mondelli RF, ElMowafy O. Effect of light curing method on volumetric polymerization shrinkage of resin composites. Oper Dent 2004;29(2):157-161.

20. Miyazaki M, Fukuishi K, Onose $H$. Influence of light irradiation on the volumetric change of polyacidmodified resin composites. J Dent 1999;27(2):149-153. [CrossRef]

21. Baek CJ, Hyun SH, Lee SK, Seol HJ, Kim HI, Kwon YH. The effects of light intensity and light-curing time on the degree of polymerization of dental composite resins. Dent Mater J 2008;27(4):523-533. [CrossRef]

22. Obici AC, Sinhoreti MA, De Goes MF, Consani S, Sobrinho LC. Effect of the photo-activation method on polymerization shrinkage of restorative composites. Oper Dent 2002;27(2):192-198.
23. Alonso RC, Cunha LG, Correr GM, De Goes MF, Correr-Sobrinho L, Puppin-Rontani RM, Sinhoreti MAC. Association of photoactivation methods and low modulus liners on marginal adaptation of composite restorations. Acta Odontol Scand 2004;62(6):298304. [CrossRef]

24. Dennison JB, Yaman P, Seir R, Hamilton JC. Effect of variable light intensity on composite shrinkage. J Prosthet Dent 2000;84(5):499-505. [CrossRef]

25. Obici AC, Sinhoreti MA, De Goes MF, Consani S, Sobrinho LC. Effect of the photo-activation method on polymerization shrinkage of restorative composites. Oper Dent 2002;27(2):192-198.

26. Yap AU, Ng SC, Siow KS. Soft-start polymerization: influence on effectiveness of cure and post-gel shrinkage. Oper Dent 2001;26(3):260-266.

27. Koran P, Kurschner R. Effect of sequential versus continuous irradiation of a light-cured resin composite on shrinkage, viscosity, adhesion, and degree of polymerization. Am J Dent 1998;11(1):17-22. 